\title{
LA RIUADA GRAN DEL XÚQUER (1864): RESPOSTES DE LES INSTITUCIONS PÚBLIQUES
}

\author{
Joan F. Mateu Bellés* \\ Universitat de València
}

Al professor i amic Dr. Eugenio Burriel de Orueta, catedràtic emèrit de Geografia Humana de la Universitat de València, per la trajectòria universitària i la dedicació honesta a la cosa pública.

Resumen: La avenida del Júcar de 4-5 de noviembre de 1864 produjo la mayor inundación de la Ribera de los últimos siglos en régimen no-regulado y uno de los mayores desastres naturales en la España del siglo XIX. La catástrofe ocurrió en un momento avanzado de la construcción del Estado liberal, una circunstancia que propició una respuesta pública más amplia de lo que había sido usual en el pasado. El artículo analiza entre las actuaciones promovidas por las administraciones (central, provincial, municipal) el socorro a los damnificados, la reparación de daños y, sobre todo, los estudios encargados a sendas comisiones de ingenieros sobre las causas desencadenantes del suceso y los medios más oportunos para aminorarlos en el futuro.

Palabras clave: Avenida extraordinaria, río Júcar, memoria de la inundación, estimación de daños, noviembre 1864, Este de España.

\section{The Great Xúquer River Flood (1864): responses by public institutions}

Abstract: The flood of Júcar river of 4-5 November 1864 was the largest flood occurred in La Ribera over the centuries and one of the worst natural disasters in nineteenth century in Spain. The disaster occurred in an advanced stage of construction of the liberal state, a circumstance that led to a more widespread public response than had been usual in the past. The paper analyzes the actions promoted by the government (central, provincial, municipal) for aid of victims, repair of damages and, above all, the studies commissioned to committees of engineers about the triggering factors of the event and the most appropriate means to minimize these events in the future.

Key words: Extraordinary flood, Júcar river, report of flooding, flood damage estimation, November 1864, Eastern Spain.

La revinguda del Xúquer de 4-5 de novembre de 1864, dita també de Sant Carles, és probablement la major crescuda registrada a la Ribera en els últims cinc-cents anys en règim natural i, amb tota seguretat, des del 1779, una constatació fundada en la superació de les marques de diverses riuades (Mateu, 1983b, 208). D'altra banda la riuada de 1864, aigües avall de la confluència del Albaida, superà en uns $35 \mathrm{~cm}$ els màxims de la pantanada d'octubre de 1982 a Carcaixent (convent de les dominiques, església de Santa Rita), Alzira (estació del ferrocarril) i Albalat (església parroquial) (Témez, 2006), tot i que també les

Data de recepció: 12 de gener de 2015 / Data d'acceptació: 16 de febrer de 2015.

* Aquest treball s'ha realitzat en el marc del projecte CSO 2012-32367. 
hi ha a l'inrevés a la vila d'Alzira. Per la superfície damnificada, i “el nombre de localitats afectades (les Riberes reunien 95.000 habitants i a la resta vivien 88.000 persones més) l'episodi va constituir una de les majors catàstrofes naturals en Espanya durant el segle XIX" (Calatayud, 2011, 1). No debades la riuada de Sant Carles fou i és una fita tràgica en la memòria de la gent de vora riu. Ara, just cent cinquanta anys després, podem documentar l'episodi de Sant Carles a partir de les diverses iniciatives institucionals desplegades davant la magnitud de la desfeta.

La gran crescuda de 1864 esdevingué en una nova etapa institucional espanyola. La construcció de l'Estat liberal es podia considerar culminada, encara que les discussions internes entre les elits polítiques i el descontentament social creixien i estava prop la ruptura de 1868. Malgrat totes les limitacions, havia aparegut una opinió pública per a la qual els esdeveniments a l'interior del país tenien interés en la mesura que afectaven a una comunitat nacional que es consolidava. Al mateix temps, l'Estat liberal aspirava al protagonisme en l'articulació del territori, la qual cosa implicava una presència eficaç en l'àmbit local durant les calamitats. En aquest context la riuada de Sant Carles es va difondre de forma ràpida, detallada i més enllà de les rodalies immediates gràcies a la premsa i als nous sistemes de comunicació, com el telègraf o el ferrocarril (Calatayud, 2011).

La desfeta del Xúquer generà una resposta pública molt més articulada del que havia estat en el passat (Alberola, 2010). La voluntat estadística de l'Estat impulsà una àmplia taxació dels danys catastròfics. També va ser molt publicitada la resposta privada, en especial els donatius destinats a pal-liar els danys. Igualment foren editats els estudis tècnics de la riuada, redactats per iniciativa del govern de S.M., a càrrec de dues comissions d'enginyers presidides per M. Bosch i J. Gómez Ortega. La revinguda també motivà la publicació d'una memòria històrica del cronista V. Boix (1865). Aquests tres textos contenen abundants descripcions, dades i interpretacions de l'episodi. Sens dubte la gran catàstrofe del país del Xúquer motivà una activa presència territorial dels governs central, provincial i municipal. Aquest article analitza les decisions de l'administració liberal, la tasca de càrrecs públics i de diverses comissions durant les setmanes posteriors a la riuada. En aquesta ocasió, s'ha optat per tractar successivament les respostes del govern de S.M., del govern de la província i dels governs locals.

\section{EL GOVERN DE S.M. LA REINA}

La voluntat del govern de S.M. fou convertir en objectiu nacional la tasca de reconstrucció de la zona damnificada ${ }^{1}$. A continuació repassarem algunes de les seues actuacions com ara la subscripció "para aliviar las desgracias causadas por las inundaciones en varios pueblos de la provincia de Valencia", i la tasca de dues comissions tècniques d'estudi per iniciativa del ministeri de Foment. També l'activitat legislativa de les Corts, amb retard, s'ocupà de la catàstrofe del Xúquer.

1 "España... sabe encontrar, en el noble vigor de su carácter nacional, fuerzas... en las circunstancias más apuradas. Así lo ha demostrado en épocas aciagas respondiendo generosa ante el infortunio... Hoy... que una calamidad inolvidable pesa sobre la provincia de Valencia..., natural es que así los altos poderes del Estado como todas las corporaciones del país concurran de consuno... a reparar en todo lo que puedan los terribles efectos de tan horroroso desastre" (Gaceta de Madrid, 19 de novembre de 1864). 


\subsection{Disposicions ministerials}

Quan el govern de S.M. tingué coneixement de la inundació, “dictó las órdenes oportunas para que fueran inmediatamente auxiliadas las primeras víctimas", mentre que reunia més informació de la magnitud de la catàstrofe. Tot d'una facilità "crecidas sumas del fondo de calamidades del presupuesto general del Estado" per a les primeres necessitats. Possiblement l'activitat protectora de l'Administració continuà amb "una suscripción nacional para socorrer con sus productos a cuantos hayan quedado reducidos a la indigencia”. Els governadors de les províncies serien els responsables del recapte en les respectives circumscripcions; les relacions ${ }^{2}$ dels donants i de les quantitats entregades serien publicades a la Gaceta i als respectius butlletins oficials de les províncies i, de forma voluntària, a la premsa diària (Gaceta de Madrid, 22 de novembre de 1864). En segon lloc, el real decret de 19 de novembre autoritzava els ministeris i, si calia, les Corts a prendre resolucions encaminades a la reparació de la riquesa (rústica, urbana i pecuària) destruïda. També el real patrimoni s'ocupà de la Ribera ${ }^{3}$.

En aquesta línia el ministeri de Foment nomenà dues comissions d'estudi de la riuada de Sant Carles a càrrec d'enginyers forestals (Gaceta del 18 de novembre de 1864) i de camins (10 de gener de 1865), presidides respectivament per M. Bosch i J. Gómez Ortega. Aquestes disposicions ministerials són l'origen de les dues primeres memòries tècniques sobre una inundació elaborades a Espanya inspirades pels principis del positivisme científic. No debades la revinguda de 1864 també fou un repte per a la ciència i la tècnica coetànies (Mateu, 1983a).

\subsection{La comissió Bosch}

Dues setmanes després de la catàstrofe "nadie conocía sino de manera vaga la extensión e intensidad del siniestro" (Bosch, 1866, XIV), però el govern de S.M. necessitava conèixer l'estat de la riquesa abans del proper abril "para el señalamiento del cupo del año 1865 a 1866". La finalitat primigènia del ministeri de Foment al nomenar la comissió Bosch no era "satisfacer una necesidad meramente científica", sinó "conocer la verdadera materia tributaria que ha quedado la desgraciada comarca de la cuenca del Júcar" (pp.

2 "La subscripció nacional era la manera en què l'administració afrontava les situacions de grans calamitats. A banda de les quantitats repartides per l'arquebisbat de València en forma d'almoines, un primer ajut pecuniari provenia de la diputació provincial que, a principis de 1865, distribuïa 835.000 reals entre les 42 pobles afectats. Aquesta quantitat havia estat recaptada, en part, mitjançant subscripció a la que havien contribuït particulars i institucions de tot l'Estat i alguna de fora, com la del Casino Español de México que va aportar el donatiu més generós de tots els registrats. L’àmplia procedència geogràfica dels donatius evidencià que la notícia de l'esdeveniment havia arribat a tot arreu i havia generat identificació emocional amb els damnificats, la qual cosa apunta a l'existència d'una certa comunitat imaginada en l'Espanya d'aquell moment. Per la seua banda, el Congrés dels Diputats, amb un cert retard, proposava en maig de 1865 un crèdit extraordinari de 12 milions de reals, dels quals 4 milions es destinaven a donatius als que s'hagueren vist reduïts a la pobresa, mentre la resta consistia en préstecs sense interés i despeses de reparació del patrimoni públic" (Calatayud, 2011, 12).

3 El real patrimoni ordenà la ràpida reparació dels dos ponts d'Alzira malmesos per la riuada, la suspensió transitòria del pagament de pontatge i de diversos censos i arrendaments (R.O. de 18 de novembre de 1864, Gaceta del 19). 
XXIII). L'objectiu de la missió consistiria en elaborar "el plano de todo el terreno que ha sufrido por consecuencia de las avenidas y los (mapes) parcelarios" indicant la intensitat dels danys ${ }^{4}$. La mampresa no s'allunyava doncs dels programes de les brigades cadastrals de la Junta General de Estadística (Muro, et al., 1996).

La comissió estava integrada pels enginyers forestals Miquel Bosch i Julià ${ }^{5}$ en qualitat de responsable ${ }^{6}$, Andrés Antón Villacampa ${ }^{7}$ de brillant trajectòria corporativa, i pels quatre primers enginyers aspirants del cos: Sebastià Vidal Soler ${ }^{8}$, José Saínz de Baranda ${ }^{9}$, Adolfo Parada Barreto ${ }^{10}$ i Andreu Llauradó Fàbregas ${ }^{11}$ (Gómez Mendoza, 1992; Casals, 1996). Pocs dies després fou agregat Fabriciano López Rodríguez, enginyer agrònom aleshores destinat a la delegació de València ${ }^{12}$.

La comissió cercà antecedents útils de personatges públics (governador, cap de Foment, senadors i diputats, rector de la Universitat, etc.), d'institucions socials (Societat Eco-

${ }^{4}$ El decret de Foment de 18 de novembre establia, a efectes cartogràfics, tres classes de danys als camps: "los que hayan quedado completamente inútiles para el género de cultivo a que han estado dedicados hasta hoy..., los que deban continuar explotándose del mismo modo que hasta la fecha..., aquellos en que sea absolutamente necesario y conveniente variar el cultivo que han tenido...".

5 Miquel Bosch i Julià (Martorell, 1818 - Madrid, 1879) pertanyia, junt a Agustín Pascual i Esteban Boutelou, a l'embrió de l'enginyeria forestal espanyola (Gómez Mendoza, 1992, 43-44). Fou professor de 1'escola del cos. A més de dos manuals, publicà la Memoria sobre la parte forestal de la Exposición de Londres de 1862 i la Memoria sobre la inundación del Júcar en 1864.

${ }^{6}$ L'enginyer en cap devia remetre a la direcció general d'Agricultura "un parte quincenal del estado de los trabajos, sin perjuicio de redactar la memoria general que presentará en este Ministerio" (R.O. de Foment de 18 de novembre de 1864). La mateixa direcció general lliurà 20.000 rs., a justificar posteriorment, per a adquisició de material i transport (R.O. de Foment de 21 de novembre). Al finalitzar els treballs, el material útil fou dipositat a Villaviciosa i a la Junta Consultiva de Montes (Bosch, 1866, X).

7 Andrés Antón Villacampa (1829-1874) fou coautor amb Agustín Romero del Plano de rodales del monte la Garganta, de los propios del Espinar, publicat el 1863 per la Junta General de Estadística, escala 1:20.000; amb aquesta experiència cartogràfica participà en la comissió d'estudi del Xúquer on hi ha un interessant Bosquejo agrícola-forestal de la cuenca del Júcar en la provincia de Valencia con indicación de los terrenos inundados, escala 1:400.000. Fundador i assidu col·laborador de la Revista forestal económica y agrícola (1868-1875), la seua mort prematura interrompre el desenvolupament d'una trajectòria eminentment naturalista (Gómez Mendoza, 1992, 47).

8 Sebastià Vidal Soler (Barcelona, 1842 - Manila, 1889) amplià estudis a Tharand on exercia Willkom. Fou president de la Comisión de Flora y Estadística forestal de las Islas Filipinas i autor, entre d'altres, de la Memoria sobre el ramo de los montes en las Islas Filipinas, Reseña de la flora del archipiélago filipino, Sinopsis de las familias y géneros de plantas leñosas de Filipinas.

9 José Saínz de Baranda elaborà, entre altres, la Memoria sobre la producción de los montes públicos de Filipinas en el año 1885-86. De retorn a la metròpoli fou director de l'escola de Villaviciosa.

10 Adolfo Parada Barreto fou l'autor de Claves dicotómicas para la determinación de tipos, clases, órdenes y familias en los reinos animal y mineral.

11 Andreu Llauradó Fàbregas (1841-1899), molt competent en qüestions hidràuliques i d'hidrologia agrícola, practicà la primera campanya d'aforaments a la conca del Xúquer (1865). A més del conegut Tratado de aguas y riegos i Hidrología agrícola de España (1884, $2^{\mathrm{a}}$ edició), redactà treballs sobre regs, auxilis de 1'Estat a les empreses de reg, futur dels canals de reg, navegació interior d'Espanya, etc. (Gómez Mendoza, 1992, 47).

12 BOPV de 30 de novembre de 1864. Fabriciano López Rodríguez fou molts anys enginyer agrònom de la província d'Alacant. Autor de Enfermedades principales de la vid. Caracteres por que se distinguen y medios para combatirlas (1889). Al pròleg indicà que estava preparant un treball "de orden más elevado y científico... sobre el conocimiento de esta provincia, con su formación geológica, con sus sierras y cerros pelados, con sus mesetas y valles, con sus variados y ricos cultivos, verdaderos oasis en medio de una estepa...". 
nòmica, Societat Valenciana d'Agricultura) i individus experts (Augusto Belda, enginyer agrònom i terratinent d'Aigües Vives; Francisco Fabra, sequier major de la Séquia Real, etc.). El 2 de desembre començà per la Ribera el reconeixement de "todo el territorio de la provincia de Valencia en que más se ha dejado sentir el horroroso temporal de los aciagos días 4 y 5 de noviembre" (Bosch, 1866, X). Les instruccions de Bosch a les brigades ${ }^{13}$ foren molt concretes: de cada terme municipal damnificat calia formar un croquis topogràfic $^{14}$ i un quadre estadístic ${ }^{15}$, acompanyats d'unes notes topogràfiques, geològiques, hidrogràfiques i agrícola-forestal. Les brigades actuaren en 83 pobles, quasi tots situats a la conca del Xúquer i malgrat les dificultats "el trabajo de reconocimiento ha dado mejor resultado del que podía esperarse" (p. XX).

L'extensió aproximada de la zona inundada més o menys malmesa era d'uns 425 $\mathrm{Km}^{2}$ i poques dificultats tindria confegir el plànol general si només ocupés la plana compresa entre Antella i la mar. La realitat però era una altra: la zona damnificada, a més de la Ribera, també comprenia franges estretes de les valls fluvials, encaixades entre muntanyes, en un territori d'uns $4.646 \mathrm{Km}^{2}$. Cartografiar doncs aquesta gran superfície, mitjançant les corresponents triangulacions, era una tasca ingent per a una comissió de tres enginyers i quatre aspirants ${ }^{16}$. A més "la medición exacta de la superficie inundada con la división parcelaria en tres clases de daños no tiene a mi juicio un interés tan grande que reclame un gasto tan considerable" (Bosch, 1866, XXII-XXIII), ni impediria engany en les taxacions. D'altra banda els danys no podien agrupar-se només en tres classes ${ }^{17}$, sinó en "una serie casi indefinida de muy difícil apreciación aún de las personas más prácticas e ilustradas" (p. XXIV).

A mitjans gener de 1865 M. Bosch proposà al ministeri una redefinició dels objectius de la comissió, el qual fou aprovat. D'altra banda, finalitzat el reconeixement dels 83 municipis damnificats, els enginyers forestals tornaren a Madrid el 23 de febrer de 1865; 1'agrònom Fabriciano López cessà i s'incorporà a la seua destinació; l'aspirant A. Llauradó restà a València per a "rectificar los datos o ampliar sobre el terreno las noticias que V.S.

13 "Cada individuo de la Comisión salió de la capital provisto de un croquis en grande escala del territorio que había recorrer, sacado de otro croquis itinerario de la provincia, y de una cartera de campo que contenía una brújula de bolsillo, una cinta de medir, una regla graduada, una carterita de dibujo, etc." (Bosch, 1866, XX).

$14 \mathrm{Al}$ croquis calia indicar les distàncies des del punt d'estació al límit municipal en les direccions cardinals i intermèdies; línies de reunió d'aigües i séquies més notables; zona inundada amb indicació de la intensitat dels danys; principals vies de comunicació; termes municipals limítrofs i situació dels respectius pobles; i les terres d'arròs (Bosch, 1866, XIX).

15 El quadre estadístic inclouria la superfície total del terme; extensió de la part inundada segons tres intensitats de danys; nombre de parcel·les inundades; superfície de la zona regada; valor de les terres segons qualitats; conreus dominants i àrea ocupada; cultius existents abans de la inundació i quins caldria introduir; característiques dels al·luvions (Bosch, 1866, XX).

16 Els plànols parcel-laris de les terres d'arròs, "de sencilla agrimensura", confegits per R.O. de 10 de maig de 1860, no aprofitaren a la comissió Bosch perque "no guardan relación entre sí..., no están sujetos a un plan uniforme..., carecen de triangulación... y muchos de ellos no ofrecen las garantías de exactitud que requiere un trabajo de la importancia que tendría el que representase la zona inundada" (Bosch, 1866, XXI).

17 En opinió de Bosch (1866, XXIII) la qüestió de les indemnitzacions als damnificats no era cartogràfica. Com que el real decret de 23 de maig de 1845 i la Instrucció de 20 de desembre de 1847 només atenien la pèrdua de collites però no la majoria dels danys registrats al país del Xúquer, calia acudir "a los cuerpos colegisladores para remediar en cuanto quepa tan extraordinaria calamidad". 
le pida desde la capital" (R.O. de 5 de febrer de 1865). A primers d'abril Bosch avançà al ministeri de Foment una ressenya $\operatorname{preliminar}^{18}$ de la riuada de 1864.

Mentre A. Llauradó, des de València, feu de pont entre M. Bosch que havia tornat a Madrid, i persones pràctiques i experts de la ciutat de València, i prosseguí el reconeixement hidrològic del Xúquer. L'aportació més important i novedosa de Llauradó fou una campanya d'aforaments (des del 8 de maig a l'11 de juny de 1865) i simultàniament la reconstrucció detallada de les seccions transversals inundades del Xúquer i afluents durant els dies 4-5 de novembre de 1864. La comparativa d'unes i altres fou l'argument per a destacar el protagonisme dels remansos a les confluències durant la revinguda de 1864 i els seus efectes destructors en hortes i artefactes de vora riu o en infraestructures viàries.

La redacció de la Memoria final i la realització de diversos dibuixos explicatius portà uns quants mesos. M. Bosch no pretenia una simple ampliació de la Reseña ja entregada, sinó "en gracia de la importancia del asunto y de lo poco que se ha escrito en nuestro país sobre cuestiones de esta naturaleza, hicimos ánimo desde un principio de extendernos en algunas consideraciones relativas a las causas de las inundaciones del Júcar, a sus tristes efectos y a los medios de remediarlos en lo posible" (Bosch, 1866, XXX). Al meu parer, els interlocutors riberencs malpensaren d'uns comissionats més preocupats de la llista dels danys que de la catàstrofe. L'objectiu fiscal generava intranquil-litat entre els damnificats molt més pendents de les ajudes del govern de S.M., de les causes i els efectes de la riuada, o de la reconstrucció dels recursos i infraestructures malmesos. Aviat M. Bosch fou conscient d'aquesta altra perspectiva, la dels damnificats, i, des de primeries de 1865, canvià el pla de treball ${ }^{19}$, per tal d'adaptar-ho a les necessitats més urgents d'un territori arrasat i desfet, ço és, a unes vores fluvials on calia recuperar les forces productives, identificar les causes destructores de la riquesa urbana, rústica i pecuària i proposar actuacions contra les inundacions del Xúquer. Des d'aquestes premisses fou elaborada la Memoria sobre la inundación del Júcar, en 1864, presentada al ministerio de Fomento por D. Miguel Bosch y Juliá... el 26 de novembre de $1865^{20}$.

La Memoria consta de "ocho reseñas"2. En las seis primeras describe el país bajo el punto de vista orográfico, geológico, meteorológico, hidrológico, agrícola y forestal”

${ }^{18}$ La ressenya incloïa la relació de poblacions afectades, els rius i barrancs desencadenants dels danys, extensió de la superfície municipal inundada classificada en tres parts segons la magnitud de la desfeta, conreus dominants $\mathrm{i}$ pèrdues registrades, justipreu de les pèrdues $\mathrm{i}$ nombre aproximat de les persones afectades (Bosch, 1866, XXVIII).

${ }^{19}$ El 1865 fou un any de canvis importants en la qüestió cadastral (PRO, 1992). Es probable que aquests contribuïren també a l'abandó de l'objectiu cartogràfic inicial de la comissió Bosch.

${ }^{20}$ S.M. la Reina donà les gràcies als comissionats "por el acierto, prontitud y economía con que han llevado a cabo sus trabajos" i, per l'interés de la Memoria, ordenà la impressió de cinc-cents exemplars a la Imprenta Real, "así como de los planos que la acompañan, que se reducirán a menor escala, refundiéndose en dos los cuatro presentados, además del de los perfiles y secciones dadas a los ríos estudiados" (Bosch, 1966, VI). Els quatre dibuixos originals representaven "un bosquejo orográfico del territorio recorrido por la Comisión", "la constitución geológica del mismo", "los cultivos y los montes dominantes" i "los ríos, ramblas y barrancos notables, así como la faja de la inundación”. Els mapes de base foren el de les províncies valencianes segons J. J. Carbonel (1935) i el del regne de València d'A. H. Dufour (1835). No hi ha constància d'ús de l'inacabat esborrany del mapa de la província de València (1860c.) de F. Coello (Rosselló, 2008).

${ }^{21}$ La terminologia (reseña, bosquejo i altres més específiques) és la pròpia de molts títols de les obres editades aleshores per la Junta General de Estadística. En realitat la monografia no s'allunya de la meto- 
(Bosch, 1866, VIII). Les altres dues estan dedicades a "los principales daños causados por la inundación" i als "medios que deberían emplearse contra las inundaciones del Júcar y de sus afluentes en la provincia de Valencia". Ara no és possible una anàlisi dels continguts amb brillants descripcions dels sistemes de conreu, de l'estat forestal de la conca o de la reconstrucció de la tempesta i l'evolució de la crescuda. La Memoria ha esdevingut una referència obligada sobre un territori en accelerat procés de canvi que la revinguda de Sant Carles precipità.

\subsection{La comissió Gómez Ortega}

A mesura que anaven passant les setmanes, el govern de S.M. fou més conscient de les dimensions de la desfeta del país del Xúquer. No era suficient la subscripció nacional, ni la única qüestió era cartogràfica i parcel·lària. El gener de 1865 el ministeri de Foment mentre aprovava una redefinició dels objectius de la comissió Bosch, en nomenà una altra integrada per enginyers de camins encapçalada per Gómez Ortega. Aquesta segona enllaçava amb la necessitat imperiosa de l'Estat d'ampliar el nombre de comissions permanents dedicades a l'estudi dels rius. Fins aleshores, per manca de personal tècnic, només s'havien constituït el 1861 les dedicades als rius de primer ordre (Ebre i Guadalquivir) amb escassos resultats (Del Moral, 1995). Tot i que la previsió era constituir-les també a les conques secundàries ${ }^{22}$, la magnitud dels danys ocasionats a la conca del Xúquer i la possibilitat de repetició aconsellà la seua immediata constitución ${ }^{23}$. D'altra banda aquesta decisió era equivalent a la d'altres estats europeus, particularment França que havia impulsat estudis tècnics de recents inundacions a càrrec de diversos inspectors generals del prestigiós cos de Ponts et Chausées (Vallés, 1857; Dupuit, 1858; etc.).

La comissió, constituïda el 3 de febrer de 1865, estava integrada per l'inspector del districte José Gómez Ortega ${ }^{24}$ i dels joves enginyers F. Lizárraga ${ }^{25}$ i E. Churruca ${ }^{26}$, alesho-

dologia ni dels resultats assolits per altres enginyers al front de les diverses brigades de la Junta. Per tant, tot i el caràcter singular de la Memoria, les sis primeres ressenyes són una bona mostra "de cierto tipo de monografías regionales que con diversos motivos y títulos, y con mayor o menor trabajo de campo, escribieron en los decenios centrales del siglo XIX tanto (enginyers) forestales como otro tipo de naturalistas" (Gómez Mendoza, 1866, 44).

${ }^{22}$ El mateix 1865 s'organitzaren primer les comissions (permanents) d'estudi del Tajo i Guadiana i al juliol es crearen deu divisions hidrològiques que abastaven el conjunt dels rius peninsulars (Mateu, 1995). Mentrestant també eren operatives les brigades de la Junta General de Estadística que prioritzaven campanyes d'aforament d'estiatge al llarg d'una conca (Mateu, 1996a).

${ }^{23}$ La decisió del ministeri de Foment fou nomenar "una comisión de ingenieros del cuerpo de caminos que bajo la dirección del inspector general del distrito de Valencia practique los estudios y reconocimientos necesarios en toda la cuenca del Júcar, y muy especialmente en la parte donde han ocurrido las últimas inundaciones, para adquirir cuantos datos puedan contribuir al conocimiento de dicha cuenca, y bajo el punto de vista de los desbordamientos e inundaciones de sus corrientes y de los medios para evitarlo o de disminuir al menos hasta donde fuera posible sus lamentables efectos" (R.O. de 10 de gener de 1865).

${ }^{24}$ José Gómez Ortega (Manzanares, 1813 - Madrid, 1886) actuà molts anys a les províncies del districte de València, des de 1841 fins 1866. Participà, entre d'altres, en l'execució de la carretera de València a Alacant per Alcoi, projecte i construcció de part de la carretera de Castelló de la Plana a Morella, ferrocarril de València a Almansa, reforma d'un tram de la séquia reial del Xúquer i obres del port de 
res destinats a la província de València. El treball exigí els mesos següents una alta dedicació especialment dels dos darrers, perquè el primer també s'ocupà simultàniament de les visites d'inspecció a les obres públiques del districte. El reconeixement de la conca del Xúquer fou extens i particularment intens als sectors més damnificats. Entrada la tardor de 1865 , la comissió ja tenia molt avançant l'estudi ${ }^{27}$. La memòria manuscrita final ${ }^{28}$, signada pels tres comissionats, estava finalitzada el 30 d'abril de 1866.

La Memoria, ajustada a les directrius de la R.O. de 10 de gener de 1865, consta de tres parts. "En la primera se hace una descripción general del río Júcar y de las condiciones de su curso desde su origen hasta la desembocadura. En la segunda se describen las anteriores inundaciones según las noticias que ha sido posible adquirir, y particularmente la de los días 4 y 5 de noviembre con exposición de sus causas, y en la tercera se trata de los medios que pueden emplearse para evitar o disminuir en lo posible sus efectos" (Gómez Ortega, et al., 1879, 6-7). Els autors, tot i ser conscients "del corto tiempo empleado y el caracter especial" de l'estudi, de la complexitat de les causes de la revinguda i la mancança d'observatoris de precipitacions i escales hidromètriques, de l'ampli ventall d'accions per minorar els danys, van elaborar un bon diagnòstic de la riuada de Sant Carles. No és possible una anàlisi dels continguts de la Memoria, raó per la qual només faré uns breus comentaris.

En primer lloc, la comissió desenvolupà un important reconeixement de la conca del Xúquer, especialment del sector corresponent a la província de València, quan ja havien passat tres mesos o més del succés i s'havien anat esborrant les petjades més fràgils. No obstant això, a més d'observar, descriure i interpretar marques, granulometries de depòsits i canvis morfològics a les vores fluvials, també cercaren informació sobre la distribució espacial i temporal de la tempesta del dia 4 de novembre, sobre la seqüència horària de les puntes de crescuda dels tributaris i, molt especialment del Xúquer a la Ribera. També procuraren valorar ordres de magnitud del temporal a Aiora i rodalies, Cofrentes i congost del Xúquer fins Sumacàrcer, la resposta sobtada del riu de Montesa, etc. Per a quadrar tantes notícies hidroclimàtiques, calia ponderar-les i discriminar-les en funció de la coherència del conjunt i guiar-se “exclusivamente por el raciocinio” (Gómez Ortega, et al., 1879, 102).

En segon lloc, els comissionats analitzaren les úniques dades meteorològiques aleshores disponibles, les de l'observatori de la Universitat de València (Tarazona, 1912) i les registrades a Carcaixent per l'exclaustrat Salvador Bodí (Mateu, 1979; Torres Faus, 1987). Amb aquesta informació, pugueren establir una comparació de les dades de pluja corres-

València. Vocal i president de la Junta Consultiva (Arxiu del Ministeri de Foment, Expedient personal 6312; Riaño, 1886).

${ }^{25}$ Francisco Lizárraga Aranguren (1839 - ?) fou un reconegut especialista en qüestions d'òptica i il·luminació elèctrica. Autor de diversos articles a la Revista de Obras Públicas, participà en la construcció de fars, entre els quals destaca el segon del cap de Vilán a la Costa da Morte el 1896.

${ }^{26}$ Evaristo Churruca (1841-1917), de llarga trajectòria, la seua figura està particularment associada al port de Bilbao. F. Sáenz Ridruejo (1990, 309-315) l'inclou en la galeria de retrats d'il·lustres enginyers de camins del segle XIX.

${ }^{27}$ Arxiu del Ministeri de Foment, Expedient personal de José Gómez, 6.312.

${ }^{28}$ La Confederació Hidrogràfica del Xúquer edità el 1988 una esplèndida reproducció facsímil de l'original manuscrit i dels gràfics que l'acompanyen. D'altra banda la Memoria fou publicada, el 1879, als Anales de Obras Públicas dins Memorias y documentos referentes a la ciencia del ingeniero y al arte de las construcciones, tom VI. En aquest article les citacions de la Memoria van referides a la paginació dels referits Anales de Obras Públicas. 
ponents als dies 4, 5 i 6 de novembre de 1864 i integrar-les en el conjunt de la conca del Xúquer: "la gran masa de agua que arrastró el Júcar se debe muy particularmente a la que cayó en el partido de Ayora $^{29}$ y parte del de Enguera. No es esto decir que los afluentes que nacen en distinta región no jugaran un papel muy importante en la inundación" (Gómez Ortega, et al., 1879, 56).

La Memoria també inclou notícies de riuades històriques consultades a l'arxiu parroquial de Càrcer i municipal de Sueca, diverses referències de les Observaciones de Cavanilles (1795-97), i cercaren "con insistencia en los archivos de algunos de los pueblos más importantes de la ribera" amb resultats molt incomplets. A més Salvador Bodí, de Carcaixent, comunicà als comissionats "las observaciones verificadas por él mismo, respecto de las inundaciones ocurridas en los últimos veinte y dos años en aquella villa", referides totes al nivell del pis de la plaça major (Gómez Ortega, et al., 1897, 51-52). A la vista d'aquestes informacions i altres de marques d'altura de grans crescudes anteriors (com les de 1779 i 1805) visibles en façanes d'edificis del país del Xúquer, la conclusió racional era que el calbal de la revinguda de Sant Carles superava els de les majors riuades precedents del Xúquer ${ }^{30}$.

Les infraestructures viàries també foren objecte de la mirada dels comissionats. La Memoria conté nombroses referències als diversos ponts existents a la conca del Xúquer i del seu estat, sovint ruïnós, després de la gran crescuda. També a les restes de vells ponts derrocats. Hi ha igualment una llarga descripció dels quantiosos danys a la via fèrria València-Almansa, molt especialment al tram de la Costera, sense oblidar els efectes del terraplè del ferrocarril quan creua la plana d'inundació, sense més desguàs que el pont sobre el Xúquer immediat a l'estació d'Alzira. Igualment de l'estat de les carreteres i de possibles vies noves per tal d'activar les zones damnificades (Ferri, 2011).

Gómez Ortega, Lizárraga i Churruca coneixien l'estat de l'art en relació als medis de defensa contra les revingudes (Vallés, 1857; Dupuit, 1858). En la seua aplicació a la vall del Xúquer demostren coneixement d'un territori ja molt antropitzat pel ferrocarril i els seus terraplens, per nombrosos nuclis de població i pel valor d'unes terres de "esmeradísimo cultivo". La intensa ocupació de la plana d'inundació i la seua geometria transversal, sovint convexa, feien impossible un sistema general de defensa de la Ribera i aconsellaren defenses locals. Aquest criteri l'aplicaren a les vores del Xúquer i afluents, des de Jalance i Cofrentes fins la desembocadura ${ }^{31}$, sense oblidar la necessària repoblació de vessants (Du-

${ }^{29}$ El partir judicial d'Aiora i part del d'Ènguera foren objecte d'una àmplia recerca d'indicis qualitatius sobre l'extensió i intensitat de les precipitacions (Gómez Ortega, et al., 1879, 53-55), una qüestió central en la reconstrucció de les causes de la gran revinguda. Per la seua banda, les dades pluviomètriques de València i Carcaixent els proporcionaren un ordre de magnituds qualitatives per al conjunt de la conca del Xúquer en el sector de la província de València i fins i tot quantitatives respecte del volum d'aigua precipitada i de la punta de crescuda (pp. 57-59).

30 Per al futur "seria de desear que en alguno de los puentes de Alcira o en el del ferro-carril se colocase una escala graduada a partir del estiaje, para llegar a tener una idea aproximada del régimen de las aguas del Júcar" (Gómez Ortega, et al., 1879, 48). La proposta s'ajustava a una R.O. de 14 de febrer de 1863 (Gaceta del 16) que manava col·locar una escala mètrica adossada als ponts construïts sobre els rius principals de la Península (Mateu, 2003).

${ }^{31}$ La Memoria també conté una destacada part gràfica. D'una banda hi ha còpies del mapa d'Espanya de Coello, del provincial de Carbonel o del que existia a la Societat Econòmica (molt probablement el de Morós i Morellón, 1847). També n'hi ha de projectes d'obres en execució a la séquia reial del Xúquer, assut de Sueca o a Carlet. La majoria són però croquis 1:10.000 confegits per la comissió i en els quals "no 
pré, 1983; Gómez Mendoza i Ortega Cantero, 1989). "Si nuestras ideas merecen aceptación..., entonces es cuando deberá procederse a un estudio mas detenido" de cada projecte (Gómez Ortega, et al., 1879, 142). Però durant dècades aquestes propostes s'oblidaren ${ }^{32}$.

\section{EL GOVERN PROVINCIAL}

A la ciutat de València, no lluny de la conca del Xúquer, les primeres notícies dels destructors efectes del temporal arribaren la vesprada del dia 4 de novembre: els telegrafistes del ferrocarril anaven informant primer dels danys a la via de València-Almansa en el tram de la Costera, després de caigudes de ponts i també de l'augment del cabal del Xúquer als voltants de l'estació d'Alzira; a la matinada del 5, de problemes al terraplè de la via a Catarroja. La desfeta de la via fèrria era senyal inequívoc d'un gran desastre general; una vegada més la veu del riu Xúquer sonà tan potent que activà de seguida una gran operació d'emergència, al front de la qual estarien les autoritats de la província i diversos col-lectius cívics. Amb el seu comportament, el personal polític de la província manifestà clarament la voluntat de l'Estat d'arribar als pobles. Al mateix temps les múltiples iniciatives del govern provincial legitimaven els que estaven immersos en la lluita política (Calatayud, 2011, 2).

\subsection{El governador de la província}

Aleshores "dirigía el gobierno de la provincia D. Celestino Mas y Abad, cuyo nombre ceñido de espléndida aureola... destaca luminoso en el sombrio cuadro de la inundación". Aquestes laudatòries paraules del cronista V. Boix (1865, 179), autor d'una informada memòria històrica de la riuada de Sant Carles, vénen precedides, a mena de dedicatòria, d'un litogravat del governador. El gest de Mas en aquesta i altres imatges del llibre i la glossa laudatòria en moltes pàgines de la crònica és una apologia de l'autoritat superior de la província amb motiu de l'emergència del país del Xúquer. El senyor C. Mas ${ }^{33}$ era un advocat de llarga trajectòria política dins la Unión liberal.

debe buscarse proporcionalidad exacta, sino simplemente una idea aproximada del aspecto general". De vegades hi ha croquis-plànols de poblacions 1:1.000 o d'elements singulars con el pont de Sant Gregori d'Alzira 1:200. La presentació gràfica no s'aparta del patró formal d'altres projectes elaborats aleshores pel cos d'enginyers de camins.

${ }^{32}$ El primer projecte de desviación del río Júcar en la parte comprendida entre los ríos Albaida y los Ojos el redactà Manuel Estibaus, aleshores destinat a la División hidrológica del Júcar y Segura, en 1886 (Mateu, 1996b), çò és, més de vint anys després de la catàstrofe de 1864 i després d'una altra gran riuada esdevinguda el 1884 .

${ }^{33}$ Celestino Mas (Igualada, 1819 - Cardona, 1883) fou alcalde d'Igualada; diputat al Congrés per Igualada vàries legislatures; governador en diverses províncies; diputat a Corts per la província de Tarragona, i autor, entre d'altres de Consultor de alcaldes y ayuntamientos (1850), Almanaque administrativo para los ayuntamientos (1855), Manual del juez de paz (1856), El libro de los jueces municipales (1871), Legislación de la época revolucionaria de España (1871). D'altra banda, el 1837 sol-licità la concessió per a portar aigua a Igualada des del riu Segre; el 1852 encapçalà una junta per a la promoció del ferrocarril entre Igualada i Martorell, i entre Igualada i Sant Sadurní. Mas fou governador de Granada durant els "sucesos de Loja" (juny-juliol de 1861). 
El governador, plenament coordinat amb el govern de S.M. des del principi de la crisi (Boix, 1865, 179), protagonitzà una activa resposta institucional. En primer lloc, visità de seguida la zona inundada per a valorar in situ la dimensió de la catàstrofe, fer visible la tutela de l'Estat als damnificats, escoltar les demandes de les autoritats municipals, coordinar mesures territorials d'emergència, i assegurar, en els primers moments, els abastaments de queviures. Segons Boix $(1865,187-188)$ el governador Mas "era la autoridad benéfica, que acude a las desgracias públicas, el genio protector de los pueblos, el padre, el amigo de los desgraciados". El mateix cronista esmenta les dificultats d'accés a la Ribera per la desfeta de vies i ponts del ferrocarril, però també de l'empenta del governador i la seua comitiva d'alts tècnics i funcionaris camí d'Alzira i Carcaixent. La primera destinació del governador (dia 5 de novembre) fou però Catarroja i en concret a la pobla de barraques, on el barranc de Massanassa n'havia arruïnat unes 170 (p. 178). Al dia següent, la primera autoritat provincial i la seua comitiva ${ }^{34}$, des de València, arribaren a migdia a Algemesí en un tren especial, tot i que part del trajecte es feu amb un trolec o avançaren a peu. Després continuaren cap Alzira ${ }^{35}$ on entraren fent-se de nit ${ }^{36}$. Tot seguit el governador presidí una reunió amb el jutge del districte, l'alcalde i les respectives comitives per tal d'acudir a les necessitats més urgents ${ }^{37}$. L'endemà a primera hora va poder contemplar la magnitud del desastre urbà. Després de donar més ordres urgents ${ }^{38}$, se'n anà amb part del seu seguici a Carcaixent ${ }^{39}$, on desenvolupà un programa d'activitats semblant ${ }^{40}$. A última hora del 7 de novembre, el governador i part de la comitiva ja estaven de retorn a València.

34 Acompanyaven al governador el cap de la Secció de Foment, el caporal de la Guàrdia Civil i el de la Companyia de Fusells, el director de Telègrafs, dos inspectors del ferrocarril, un enginyer i un ajudant d'Obres Públiques, l'arquitecte provincial, l'inspector de vigilància, etc. (Boix, 1865, 182). El cronista els comparà, amb evident exageració, a "aquellos osados viajeros que, por amor a la ciencia, iban a estudiar en las regiones pantanosas de la América, del África central, del Asia y de la Nueva Holanda” (p. 183).

35 Segons Antonio Sancho, arquitecte provincial, hi havia un total de 684 cases malmeses per la riuada, de les quals 100 estaven totalment assolades, $58 \mathrm{mig}$ assolades, 273 parcialment assolades, 203 més o menys ressentides i 50 amenaçaven ruïna. L'alternativa transitòria consistí en l'apuntalament de 463 cases, mentre calia derrocar-ne 109. Amb aquesta estadística, cal deduir un panorama dantesc a la vila i al raval d'Alzira, coincident amb les imatges de diversos gravats inclosos a la Memoria histórica de V. Boix (1865).

${ }^{36}$ El gravat de l'entrada del Governador de la província i el seu seguici a la vila d'Alzira és una icona de la riuada de Sant Carles glossada per Boix $(1865,186)$ : "Cruzando por una casa, penetraron en las calles más elevadas, sumidas en la más profunda e imponente soledad, cubiertas todas por una gruesa capa de agua fangosa... y saltando por encima de animales muertos y objetos destrozados, llegaron todos, cerrada ya la noche, a la antigua e histórica casa de la villa, donde pudo enterarse el intrépido gobernador de la extensión de la catástrofe".

37 "La primera necesidad era acallar el hambre... se enviaron comunicaciones urgentes a los alcaldes de Algemesí y Alberique, para que remitiesen 6.000 panes; pero el mensajero solo pudo llegar al primer pueblo, pues era imposible aproximarse al segundo" (Boix, 1865, 188). Al dia següent a migdia ja s'havien distribuït a Alzira 2.000 pans enviats per l'alcalde d'Algemesí.

38 “...A pesar de la dificultad el ayuntamiento consiguió formar algunas escuadras, que comenzaron a arrojar al río los animales muertos; y se recogieron 21 cadáveres humanos, que se encontraban esparcidos por las calles" (Boix, 1865, 190).

39 (Carcaixent) "no ofrecía ciertamente... el aspecto desolador de Alcira". Hi havia un total de 280 cases damnificades, de les quals 25 completament en ruïna total, 159 en ruïna parcial i 96 declares de perill imminent (Boix, 1865, 140).

40 Entre d'altres aprovà les mesures adoptades per l'alcalde i oficià als de Tavernes, Simat i Gandia per tal que subministraren queviures als damnificats. També ordenà que no s'incrementaren els preus dels articles de primera necessitat (Boix, 1865, 191). 
El governador Mas tornà a la Ribera per a visitar "los desolados campos de Alberique donde, según el parecer del alcalde... fueron a parar unas 14.000 piezas de madera" transportades pel desbordament del Xúquer i que havien agreujat els danys en ponts, assuts, séquies, poblacions i arbrat. El transport de troncs pel riu havia estat "causa principal de los terribles males", segons la primera autoritat provincial ${ }^{41}$ (Bosch, 1866, 387).

A més d'aquestes i altres visites als pobles damnificats, el governador envià diverses circulars al Boletín Oficial de la Provincia de Valencia (BOPV). Així en atenció a que "uno de los primeros deberes a que debe atender mi autoridad (és) el de velar por la salud pública", ordenà als alcaldes la incineració d'animals morts, especialment als dels pobles de vora mar i de vora riu, per tal d'evitar qualsevol motiu d'infecció ${ }^{42}$. També donà instruccions per a reclamar els troncs escampats, particularment a les rodalies d'Alberic, per efecte de la riuada ${ }^{43}$.

D'altra banda, el governador Mas se'n adonà que "la pérdida sufrida (a la zona damnificada) ha sido escasa en las cosechas, al par que grande en la riqueza rústica, urbana y pecuaria", una circumstància no prevista per la legislació aleshores vigent. Allò previst eren indemnitzacions per la pèrdua parcial o total de collites i ramats. Calia, en opinió de la primera autoritat provincial, instruir els expedients de danys per causa d'una calamitat extraordinària per tal que el Govern de S.M. proposés a les Corts la via d'indemnització. En conseqüència calia instruir els expedients de forma meticulosa ${ }^{44}$ per tal que el govern de S.M. apreciés el caràcter extraordinari dels danys ${ }^{45}$.

El governador civil també informà de l'arribada a València de la comissió facultativa presidida per l'enginyer Bosch $^{46}$ i sol·licità la màxima col·laboració als alcaldes, juntes de

41 Enterat de la desfeta de Tous, la mateixa jornada també rebé una comissió presidida pel seu alcalde. "Su relación (de la catàstrofe de Tous) conmovía las entrañas. La autoridad superior se apresuró a entregar diez mil reales, para atender las primeras necesidades, disponiendo además que se pusiera en servicio inmediatamente la barca de aquel pueblo que había quedado de todo arruinada" (Boix, 1865, 44).

${ }^{42}$ BOPV, 11 de novembre de 1864.

43 BOPV, 14 de novembre de 1864. "Los que se consideren con derecho a las maderas deben reclamarlos ante los alcaldes respectivos, dentro de diez días, acompañado del documento que expida el alcalde del punto de donde procedan las maderas".

44 "La Autoridad superior de la provincia, con la inteligencia y el celo que todos le reconocen, ha adoptado medidas enérgicas para conocer la verdadera naturaleza tributaria que ha quedado en la desgraciada comarca de la cuenca del Júcar; pero como son tantas las pérdidas, y tantos los perjudicados, y grande el anhelo por recibir auxilios, y poca la ilustración de los Alcaldes y Secretarios de los Ayuntamientos de los pueblos de corto vecindario, y poco reflexivo el deseo de los tasadores por aliviar la suerte de sus deudos y amigos; es de temer que por más que la ley amenace a los que cometan faltas en las relaciones de los daños que hayan sufrido, la ignorancia en unos casos y el dolo en otros hagan que no siempre se presenten las relaciones de las pérdidas con la exactitud apetecible" (Bosch, 1866, XXIV).

45 BOPV, 18 de novembre de 1864. Hi ha comunicació governativa sobre les "reglas y forma a que han de sujetarse los ayuntamientos de los pueblos de esta provincia que han padecido perjuicios por la reciente inundación para instruir los expedientes de perdón de contribuciones por todos conceptos". En la confecció de l'expedient municipal calia la participació de tres dels majors contribuents, certificat de dos pèrits agrònoms, d'un mestre d'obres i relacions de collites dels dos anys anteriors i dels propietaris que calia perdonar la contribució. Posteriorment, BOPV d'11 de desembre, el governador ordenà als ajuntaments reomplir un model amb cinc relacions diferents de danys (pèrdues a títol personal, pèrdues totals del poble i terme, danys d'edificis municipals i camins, danys en les séquies; danys de temples). Segons el BOPV de 15 de gener de 1865, encara no havien arribat a la seu del Govern de la província tots els expedients municipals de danys. A primers de febrer de 1865, una nova circular invalidava els expedients i calia refer-los ajustant-se a un nou model emanat del govern de la província.

46 BOPV, 30 de novembre de 1864. 
govern de les séquies, "empleados y dependientes de mi autoridad". D'altra banda, demanà als alcaldes de Cofrents, Alberic, Carcaixent i Alzira que, consultats els antecedents necessaris, li contestaren "en qué meses del año han ocurrido generalmente las avenidas del Júcar, y en qué años han sido las mayores” (Bosch, 1866, 133).

A primers de febrer de 1865, el governador Mas deixà el govern de la província de València amb destinació al Congrés dels Diputats al haver estat elegit en representació de la província de Tarragona. En síntesi, a més de coordinador de l'administració provincial, dedicà les primeres jornades al reconeixement in situ de la dimensió de la catàstrofe i visibilitzà la presència de l'Estat davant les autoritats municipals en la fase d'emergència; en les setmanes posteriors impulsà l'elaboració d'estadístiques homogènies dels danys en la riquesa rústica, urbana i pecuària. En tot temps mantingué informat al govern de S.M.

\subsection{La Diputació provincial}

"Mientras las autoridades superiores se dedicaban, desde el primer momento de la catástrofe, a llevar el consuelo a los infelices habitantes de la Ribera, la diputación provincial,... se reunió; y ... adoptó prontas, enérgicas y eficaces medidas" (Boix, 1865, 211212). Una comissió de set diputats s'ocupà d'atendre la situació i activar la reparació dels danys; obrir una subscripció per a necessitats urgents i sense dret a indemnització; i sol·licitar a S.M. l'ampliació del termini legal de 8 dies "de formar los expedientes en crédito de los perjuicios sufridos” (pp. 213-215). La comissió assolí d’immediat la realització d'una subscripció ${ }^{47}$ mitjançant la creació de juntes parroquials encarregades d'una col·lecta general a la ciutat i província de València, amb la col·laboració de l'arquebisbat. També preparà normes per a la formació d'expedients de danys a càrrec dels ajuntaments ${ }^{48}$. Igualment s'ocupà de l'abastament de $\mathrm{pa}^{49}$, de la crema d'animals morts, de convocar a la Junta provincial de sanitat.

D’altra banda, part de la comissió passà a Alzira el dia 8 de novembre per tal d'actuar in situ. La mateixa jornada també hi anaren "cuarenta y cuatro individuos de la brigada de zapadores-bomberos... y algún material y setenta trabajadores de los que el ayuntamiento (de València) tenía destinados al empedrado de calles y arreglo de paseos, con algunos carros, también de la municipalidad para atender a la extracción de caballerías y cuanto fuera necesario" (Boix, 1865, 224). A última hora del dia 9, els operaris municipals de València ja havien retirat d'Alzira totes les cavalleries mortes i tenien avançat la neteja de carrers i l'apuntalament de cases. El governador, de retorn d'una visita als pobles de la Ribera, informà molt favorablement del treball de la brigada de neteja. El dia 13 s'acordà re-

47 BOPV, 10 de novembre de 1864. Al mateix temps la comissió demanà que la subscripció fos nacional, la qual cosa fou acceptada (Gaceta de Madrid, 19 de novembre de 1864).

48 BOPV, 18 de novembre de 1864.

49 El dia 9 de novembre de 1864 "fue llamado Vicente Martí y Marsal, dueño de la fábrica de amasar pan, situada en el molino de la Esperanza (de València), y se estipuló suministraría la cantidad de raciones que dispusiera la comisión al precio de 19 maravedís libra... previniéndole presentase muestra para poder convencer de su buena calidad, la que en efecto presentó" (Boix, 1865, 226-227). Però "el día 11 se presentó una comisión de horneros de la capital, ofreciendo 5.000 raciones de pan que tenían elaboradas, con destino a los pueblos de la Ribera, y la comisión adoptó las medidas... para que llegasen a su destino, suspendiendo la fabricación de pan” (ja acordada amb V. Martí) (p. 230). 
tirar-la, deixant només una secció de vint manobres i fusters fins el dia 20 de novembre (pp. 230-233).

La diputació prorrogà la situació d'emergència fins el dia 19 de novembre. A finals de novembre l'organisme havia gastat 80.748 rs. i disposava de 536.130 rs. rebuts per subscripció, sense incloure 40.000 rs. del fons de calamitats i altres 40.000 d'imprevistos. Mentre no hi hagués informació detallada dels danys per a una distribució equitativa dels recursos, la diputació acordà aportar recursos per a la neteja i recomposició urgent de séquies "en calidad de reintegro por el de la suscripción nacional u otros caudales que proporcione el gobierno con las Cortes para indemnización de pérdidas" (Boix, 1865, 216-221).

\subsection{La junta provincial de sanitat}

La junta provincial de sanitat creà una comissió especial per assessorar les autoritats en l'adopció de mesures de prevenció de malalties de funestes conseqüències. A més "la historia médica de los pueblos ribereños, naturalmente pantanosos..., nos ofrecen tristísimos recuerdos de las numerosas víctimas que ocasionan". La comissió, desplaçada a Alzi$\mathrm{ra}^{50}$, celebrà la primera sessió el dia 11 de novembre amb l'avaluació de l'estat sanitari de la Ribera on molts cereals guardats en dipòsits s'havien remullat per la riuada, hi havia nombrosos cadàvers d'animals a les vores del riu i a la platja immediata a la desembocadura, $\mathrm{i}$ als corrals de les cases $\mathrm{i}$ als camps hi havia productes vegetals $\mathrm{i}$ animals que aviat entrarien en descomposició (Boix, 1865, 236-244).

A Alzira les autoritats locals havien autoritzat tirar al riu 962 animals majors morts per tal d'allunyar el problema de la ciutat ${ }^{51}$, i "una considerable cantidad de granos averiados", la qual cosa havia degradat encara més les condicions sanitàries del Xúquer. D’altra banda, les necessitats del moment havien obligat a les autoritats a enterrar 27 cadàvers a l'església de Sant Joan sense massa condicions higièniques. El quadre sanitari no era millor als corrals de les cases, focus potencials d'infeccions al barrejar-se el fem amb el fang de la riuada. Mentre a les eres hi havia molt d'arròs amb excés d'humitat en procés de putrefacció i/o germinació que els propietaris procuraven secar amb l'objectiu de transformar-lo en pinso o per a barrejar-lo amb arròs bo. Com, a més, era previsible un "patiment especial" de la població, la comissió acordà també l'habilitació de noves sales a l'hospital de Santa Llúcia i l'organització del servei sanitari local per absència dels subdelegats de medicina i farmàcia (Boix, 1865, 241-242).

En vista de la situació general i en particular d'Alzira, la comissió adoptà mesures desinfectants i antisèptiques ${ }^{52}$ que foren comunicades a les respectives juntes municipals de sani-

\footnotetext{
${ }^{50}$ La diputació provincial oferí "un botejón de ácido nítrico y una arroba de desperdicios de cobre, quedando en remitir la cal que pudiera reunirse". Més avant s'enviaren "diez y nueve y medio cahíces de cal, detenidos a la puerta de la ciudad (de València), por no haber sido posible encontrarla por otro medio" (Boix, 1865, 228-229).

${ }^{51}$ Aquesta pràctica resolia el problema local, però el traslladava aigües avall fins les rodalies de $\mathrm{Cu}$ llera, llocs que a més havien acollit desplaçats d'Alzira, on "la emigración había sido casi completa" (Boix, 1865, 241).

${ }^{52}$ La Comissió no "reconoció una acción tan rápida y enérgica como en la que producen los ácidos y principalmente los del reino inorgánico... Estas consideraciones obligaron a la comisión a decidirse por el ácido nítrico, para rociar las sustancias que se hallaban en completa descomposición, y que su presencia en cualquiera parte siempre es deletérea y altamente nociva a la salud pública" (Boix, 1865, 244).
} 
tat, entre les quals l'obligació de ruixar amb àcid nítric totes les substàncies animals i vegetals en descomposició. Igualment ordenà la desinfecció, tantes vegades com fora necessari, de l'església de Sant Joan d'Alzira i d'alguns corrals i cases, la inutilització de cereals i llegums avariats, la prohibició de beure aigua del riu Xúquer, la neteja de corrals i quadres i la prohibició d'inhumacions al cementeri excepte als nínxols (Boix, 1865, 243-246).

Finalitzada la missió a Alzira, els sanitaris passaren a Cullera per avaluar la situació a la desembocadura del riu i a la platja, i celebrar una reunió amb l'ajuntament i la junta municipal de sanitat, durant la qual s'acordà que "atendida la dificultad de desenterrar aquellos (animales muertos) que habían aparecido antes de nuestra circular, se les cubriese con una gruesa capa de cal, y respecto a los demás se procediese a su ustión" (Boix, 1865, 246-247).

Per últim els sanitaris traslladaren al governador les greus conseqüències que podien derivar-se'n de l'ús de l'arròs, fesols, forment i altres grans avariats "que se dice se hallan ya circulando en los mercados y se pueden emplear en forma de harinas para adulterar otras de la misma naturaleza y para ciertas industrias mezcladas con el chocolate y otros productos alimenticios". En síntesi, els comissionats estaven segurs d'haver acordat "cuantos medios la ciencia reconoce, capaces de impedir el desarrollo de alguna epidemia" (Boix, 1865, 247-248).

\subsection{La societat civil. La Sociedad Valenciana de Agricultura}

La resposta de les institucions provincials davant la desfeta de la riuada de Sant Carles no pot deslligar-se de la gran mobilització col·lectiva, encapçalada per la ciutat de València amb diverses iniciatives solidàries des de les parròquies fins les noves formes de socialització (tertúlies, moviment estudiantil, etc.) ${ }^{53}$. Per la rellevància de les aportacions tècniques a l'estudi de la riuada liderat per l'enginyer Bosch i Julià, ací només consideraré la contribució de la Sociedad Valenciana de Agricultura.

La Societat Valenciana d'Agricultura (S.V.A.), fidel a "ese espíritu protector de la agricultura del país que es el carácter distintivo de la sociedad" i vista la dimensió de la calamitat, tot d'una sol-licità del govern de S.M. la supressió de l'impost directe i el de consums als pobles damnificats per cinc anys, amb l'objectiu de rehabilitar la propietat i la riquesa a les vores del Xúquer (S.V.A., 1864a, 387-389). Al si d'aquesta societat de les elits agràries, hi havia molta preocupació pel futur de la Ribera perquè la gran revinguda havia esdevingut en un període crític i calien mesures coordinades i urgents per a restablir aviat l'activitat productiva (S.V.A., 1864b, 408). Així A. Belda (1864, 455-460), enginyer agrònom, baró de Casanova i secretari de la societat, observà l'encert de les primeres plantacions de forment després de la riuada i animà a ampliar-les amb altres cereals, faves, creïlles, etc. El mateix Belda $(1865,162-165)$ proposà mesures preservatives senzilles als camps contra els danys de les riuades (bardisses d'arbres, malecons, etc.). També S. Bodí (1866, 431-436) explicà el paper d'actuacions menors profitoses i de baix cost a la zona inunda-

53 La dimensió cívica de les distintes iniciatives solidàries mereix una investigació més detinguda, des de la proposta d'una col·lecta general a la ciutat i província de València a càrrec de juntes parroquials per iniciativa de la diputació fins les visites a Alzira tant de dirigents progressistes (encapçalats per Peris i Valero) com moderats (amb el baró de Casanova al cap). 
ble, "viéndose por otra parte lo poco que se ha hecho después de la tan triste célebre inundación del 64, las pocas esperanzas de que se haga cosa alguna, y la imperiosa necesidad que hay que hacer".

La societat oferí a la comissió M. Bosch (1866, XII) la col·laboració de "personas bien conocidas por su ilustración y amor al país" i els seus coneixements pràctics ${ }^{54}$. Fins i tot algun soci compartí alguna jornada de camp. L'enginyer M. Bosch incorporà a la $\mathrm{Me}$ moria comentaris i notòries intuïcions de Belda ${ }^{55} \mathrm{i}$ altres socis sobre agricultura, però també sobre la gènesi de les precipitacions torrencials, etc.

\section{ELS GOVERNS MUNICIPALS}

El caràcter recurrent de les inundacions de les vores del Xúquer i dels seus tributaris havia situat històricament les autoritats locals al cap de les primeres accions d'emergència. Aquesta fou també la nota durant la catàstrofe de 1864. Així les autoritats locals de Catarroja, durant les hores crítiques de la pobla de barraques, adoptaren "todas las medidas que en su actividad y celo creían convenientes para salvar las personas y los edificios" (Boix, 1865, 50). L'alcalde d'Albalat de la Ribera feu un ban amb mesures d'alerta i, durant el desbordament, "embarcó en una lancha, y auxiliado por dos hombres, navegó por las calles, con el fin de prestar auxilio" (p. 55). Aquesta fou la tònica dels regidors en tantes altres poblacions abans i durant la revinguda ${ }^{56}$. També intervingueren en les primeres hores el jutge del districte d'Alberic i el d'Alzira. Així el primer es trobava a Càrcer, amb el seu seguici, per qüestions judicials i, juntament amb l'alcalde constitucional, s'ocupà de dirigir el rescat dels carrers més baixos de la vila i després passà a Cotes per a avaluar la situació (pp. 95-99). El jutge del districte d'Alzira, juntament amb l'alcalde, "adoptaron prontas y eficaces medidas, para hacer frente a la penosa situación que les rodeaba" (p. 156). A més les autoritats constitucionals locals, visibles en les accions de salvament i rescat de la població, tingueren el suport valerós i arriscat de la guàrdia civili ${ }^{57}$, una disponibilitat molt elogiada pel cronista V. Boix (1865).

${ }^{54}$ La societat nomenà una comissió formada per Augusto Belda, Vicente Ferrer Fuertes, Joaquín Pardo de la Casta, José Royo Salvador i Francisco de Paula Rochano, "con la cual (M. Bosch) pudiese conferenciar caso que creyese oportuno su cooperación” (S.V.A., 1865, 4).

55 Segons Bosch (1866, XVI), A. Belda “conocedor de las prácticas agrícolas de su país y de los adelantos que ha hecho la ciencia agraria en el extranjero, donde lo ha estudiado dejando muy bien puesto el nombre español, no abandonó un momento a la Comisión. Nos designó varios puntos dignos de estudio bajo el punto de vista hidrológico, y aún nos acompañó en algunas excursiones que no estaban exentas de peligro". Així en la primera visita dels comissionats a Barx (12 de gener de 1865), "un cráter de depresión” segons Bosch (p. 77), participà el baró de Casanova (p. 70).

${ }^{56}$ La narració de Cullera conté escenes molt plàstiques que il·lustren el paper de l'autoritat local. Un ban de l'alcalde, a última hora del dia 4 de novembre, alertà del perill imminent i obligà il·luminar els edificis. Poc després quan el riu inundà molts carrers de la vila, "la multitud de luces, expuestas en los balcones, ventanas y azoteas demostró que todos los vecinos se hallaban vigilantes y prevenidos". En aquests moments "se procedió a salvar en la parte más baja de la villa las personas y ganados de labor". Finalment a les 2 h. del dia 5 de novembre, presidits per l'autoritat local, s'inicià el trasllat de la Mare de Déu del Castell a la vila, "una larga procesión de luces sobre la sombra oscura del monte". Una hora després les aigües del Xúquer començaren a remetre i a les 15 h. ja havien tornat al seu caixer (Boix, 1865, 168-170).

57 Els guàrdies del seguici del jutge d'Alberic evacuaren majors, dones i menuts del carrer de Sant Roc de Càrcer (Boix, 1865, 95). Dos guàrdies del puesto d'Ènguera assajaren salvar la vida de quatre 
L'endemà de la gran riuada, quan les aigües desbordades remetien i el cabal tornà al caixer ordinari de rius i barrancs, es feu palesa la dimensió de la catàstrofe. Els primers moments foren de mirada incrèdula dels damnificats davant la devastació de les viles ${ }^{58} \mathrm{i}$ els camps productius poques hores abans, i de desolació davant un paisatge d'“agua, fango, cieno, cadáveres, ruinas en la villa; campos arrasados, árboles destrozados, canales perdidos, acequias cegadas, y el hambre... Eran los funestos objetos que destacaban... de aquel lienzo que había bosquejado la misma naturaleza en una de sus espantosas conmociones" (Boix, 1865, 141). L'autoritat local no es podia detindre però davant "extensos pedregales y playas de arenas que dejaron al pueblo (de Cofrentes) rodeado de un árido desierto" (p. 77), ni "de aquel vasto campo de devastación” (d'Anna) (p. 90), perquè "el hambre y la miseria mostró al día siguiente su descarnada faz" (p. 111). Alcaldes i regidors adoptaren decisions "amb rapidesa, quasi com en un ritual al que devien estar acostumats. D'aquesta rapidesa depenia que la catàstrofe no s'ampliara més" (Calatayud, 2011, 6); era urgent aconseguir l'abastament de la població i la neteja de carrers per a recuperar la normalitat de la zona damnificada, dues tasques difícils amb els recursos limitats dels governs locals. Per tal de culminar-les les autoritats provincials aportaren efectius humans i materials, especialment a Alzira i també a Carcaixent. Neteja i abastament atorgà també visibilitat a les autoritats provincials i locals de l'Estat liberal.

L'aliment bàsic, el pa, no es podia elaborar en molts indrets i la farina s'havia fet malbé; la llenya i els forns estaven enfangats. "Les autoritats, familiaritzades amb el perill social que la manca d'aliments representava" (Calatayud, 2011, 7), tractaren de “... proporcionar al vecindario lo preciso para que la cuestión de subsistencias no aumentase la desgracia y crease un conflicto" (Bosch, 1866, 341). Aquesta qüestió també té interés perquè ens mostra que els recursos que es podien mobilitzar ràpidament tenien procedència local i la transferència massiva de productes era limitada (Calatayud, 2011, 7). Els primers auxilis alimentaris van arribar dels pobles veïns. Així a Carcaixent se va rebre pa de Xàtiva i per via fèrria dels pobles de la Valldigna i, fins i tot, de Gandia; Alzira va ser auxiliada des d'Algemesí i Guadassuar; Albalat de la Ribera, des d'Algemesí; Benimuslem des d'Alberic. La solidaritat entre pobles veïns fou reforçada amb ordres explícites del governador de la província als alcaldes de la perifèria no damnificada i amb gestions directes de la diputació davant forners de la ciutat de València.

Els alcaldes i regidors, "adoptaron cuantas medidas les parecieron oportunas" i iniciaren també la neteja dels carrers i altres espais públics. A Alzira la primera actuació fou recuperar els cadàvers humans, especialment a l'interior de les cases derrocades, i enterrar-los a l'església de Sant Joan; després apuntalar les cases que amenaçaven ruïna i al mateix temps

operaris d'una instal·lació manufacturera d'Anna, sense aconseguir-ho (p. 90). Els efectius del quarter de Carcaixent participaren en missions de rescat de persones i animals, alguna especialment arriscada (pp. 136-137). També a l'Olleria (p. 95), Alzira i altres poblacions. Probablement la primera ajuda urgent a la vila devastada de Tous, "como instrumentos de la Providencia", fou l'arribada del sergent i dos guàrdies civils del puesto de 1'Alcúdia. El Boletín Oficial de la Guardia Civil se'n feu ressò d'aquests i altres accions de membres del cos armat.

58 El panorama d'Alzira era dantesc: "Bazares sin artículos, almacenes sin mercancías, departamentos sin mobiliario en desordenada confusión, familias enteras ocupadas en desalojar sus viviendas de los inservibles y destrozados restos de sus fortunas, obstruidas las calles por los cadáveres de animales..." (Boix, 1865, 155-156). 
llançar al riu Xúquer els animals morts ${ }^{59}$ (Calatayud, 2011, 6-7). L'operació de neteja d'Alzira ultrapassava la capacitat local i la completaren brigades enviades des de València.

Mentrestant molts habitants dels pobles més malmesos havien anat deixant l'habitatge habitual i se'n anaren a viles i alqueries immediates. Molta gent d'Alzira anà acollida a la Ribera Baixa (Boix, 1865, 241). Però el retorn a casa exigiria també treball per als molts jornalers, un requisit necessari segons la primera autoritat local de Carcaixent ${ }^{60}$. Foren jornades d'incertesa i de moltes dificultats per a reconstruir el sistema productiu, la qual cosa exigí, un major endeutament, revisió d'arrendaments, etc.

Les autoritats provincials, en consonància amb l'afany estadístic del govern de S.M., havien emprés una campanya de taxació dels danys de la revinguda. Els alcaldes foren designats responsables d'elaborar l'oportú expedient de taxació, atenent a criteris i formularis que variaren tres vegades en els quatre mesos posteriors a la gran revinguda. Cada poble remeté l'expedient al govern de la província demanant l'auxili econòmic oportú, atenent els diversos apartats estipulats en els formularis. Aquesta documentació fou la base per a elevar al govern de S.M. una estadística de la desfeta del Xúquer, en vista de la qual acordà una indemnització ${ }^{61}$. La tramitació i resolució de l'expedient a València i Madrid mereix una anàlisi detallada.

Però més enllà de les institucions públiques, la gent de vora riu protagonitzà la reconstrucció de les hortes i instal-lacions manufactureres o la reparació provisional de les infraestructures hidràuliques en els mesos immediatament posteriors a la catàstrofe. Bosch $(1866,303)$ no tenia paraules "para enaltecer la laboriosidad de los ayorinos. Los sacrificios que están haciendo para crear nuevas huertas... excede a toda ponderación”. Igualment cita Sumacàrcer on s'havien fet "los mayores esfuerzos para volver a formar huertas en las orillas del Júcar" (p. 316) i s'admirava de l'activitat dels llauradors de Cullera. Al juny de 1865 els regants d'Antella ja havien aconseguit reparar provisionalment la séquia (p. 178), a l'igual que els de la séquia reial (p. 180). Però sobre tot, la gent del país del Xúquer demanava, per a superar la crisi, que "el Gobierno de S.M. les permitiera extender el cultivo del arroz", "una afición que raya la locura" (Bosch, 1866, 236).

\section{CONCLUSIÓ}

La dimensió social, econòmica i mediàtica de la revinguda gran del Xúquer també impactà sobre les institucions públiques, les quals assoliren una gran visibilitat en la gestió

${ }^{59}$ A Alzira "había perecido casi todo el semoviente y si violentando algunos caballos se logró sustraerles de la suerte de los demás, se resentían y apenas podían prestar el servicio menos fatigoso. Sin embargo, el patriotismo y desprendimiento de los señores Galvañón les indujo a facilitar su yunta (de bous) con la que se arrastraron y arrojaron al río los que se veían en las plazas y calles más públicas" (Boix, $1865,341)$.

60 "En Carcagente no se humilló al proletario. El alcalde comprendió que había escasez de pan, no necesidad de darle. Se procuró que no faltase el trabajo al pobre jornalero y que se le vendiesen los artículos de primera necesidad al precio más bajo posible" (Bosch, 1866, 341).

${ }^{61}$ El 12 d'octubre de 1874, ço és deu anys després de la catàstrofe de Sant Carles, la diputació provincial assignà el muntant de la indemnització a cada poble damnificat. Per la seua banda, a les acaballes de 1874, els ajuntaments començaren a repartir la subvenció als afectats (Martí Soro, 1960, 111). 
de la catàstrofe. Les administracions es van fer presents "mitjançant actuacions que ens situen en les pràctiques administratives i polítiques de 1'Estat contemporani, en aquell moment en procés de consolidació a Espanya" (Calatayud, 2011, 23). Moltes foren les accions desplegades des dels ministeris fins els ajuntaments: ajuts directes i indirectes, proximitat als damnificats, memòries i informes de diverses comissions impulsades pels governs de S.M. o de la província, expedients amb la taxació de danys de diverses classes, treballs cartogràfics, etc. Aquesta pluralitat d'iniciatives públiques generaren un voluminosa documentació amb les actuacions de les diverses administracions competents al país del Xúquer superior a qualsevol altra riuada anterior a la pantanada de 1982.

La dimensió de la catàstrofe ultrapassava de molt el marc legal vigent que només atenia indemnitzacions per pèrdua de collites. A més els governs (locals, provincial i de S.M.) només disposaven de les reduïdes partides pressupostàries assignades a "calamitats" i “imprevistos". Des d'aquesta perspectiva s'entén millor la inicial perspectiva tributària i cartogràfica del govern de S.M. o la ràpida proposta de col·lecta a instància de la diputació provincial. Molt aviat però el governador Mas, de visita a la Ribera, se'n adonà que la pèrdua de collites al mes de novembre era relativament escassa, però molt gran la desfeta en riquesa rústica, urbana i pecuària. Calia doncs instruir expedients de danys per causa de calamitat extraordinària, una realitat que devia assumir-la les Corts i aprovar una partida extraordinària i finalista. Aquesta opció va exigir una alta dedicació dels alcaldes en la confecció dels expedients amb els danys desglossats amb criteris estadístics homogenis, una tasca amb grans limitacions als pobles menors.

Per la seua banda les iniciatives protectores (bans d'alerta, accions de salvament, primera repartició de queviures, etc.) de les autoritats locals (alcaldes i regidors, jutge de districte, guàrdia civil, funcionaris), "amb rapidesa, quasi com en un ritual al que devien estar acostumats" (Calatayud, 2011,6) supliren els escassos recursos de les administracions municipals. Les autoritats provincials s'incorporaren immediatament a les tasques més urgents (abastament, neteja) per tal de recuperar la normalitat, tot i que per ara només hi ha informació sobre Alzira i, en menor mesura, Carcaixent i alguna altra gran població. Caldrà aclarir el grau de visibilitat de l'administració provincial a les viles menors, i especialment a les més aïllades i destruïdes, com fou el cas de Tous en els anys posteriors a la revinguda.

Les institucions públiques liberals, confiades en la utilitat del positivisme científic, activaren comissions d'estudi (la dels enginyers de camins i la dels forestals), comissions executives (diputació provincial) i comissions assessores (sanitat) per a la gestió dels diversos indrets durant les distintes fases de la gran calamitat del Xúquer. Malgrat la pluralitat de respostes públiques, algunes ben novedoses a Espanya, les escasses indemnitzacions tardaren deu anys i les recomanacions de les comissions tècniques no s'executaren en els anys posteriors. Sens dubte les administracions de l'Estat eren molt dèbils per a reparar i reconstruir una desfeta que s'havia afegit a la crisi econòmica, social i política que vivia el país del Xúquer.

\section{BIBLIOGRAFIA}

ALBEROLA, A. (2010): Quan la pluja no sap ploure. Sequeres i riuades al País Valencià en l'edat moderna, València, Publicacions de la Universitat de València, 251 p.

BELDA, S. (1864): "Remedios contra la inundación”, La Agricultura Valenciana, II, 21, 406-408. 
BELDA, S. (1865): "Preservativos contra los efectos de las inundaciones", La Agricultura Valenciana, III, 8, 162-165.

BODÍ, S. (1866): "Preservativos contra las inundaciones", La Agricultura Valenciana, IV, 20, 431-436.

BOIX, V. (1865): Memoria histórica de la inundación de la Ribera de Valencia en los días 4 y 5 de noviembre de 1864, Valencia, La Opinión, 263 p.

BOSCH Y JULIÁ, M. (1866): Memoria sobre la inundación del Júcar en 1864, Madrid, Imprenta Real, 424 p.

CALATAYUD, S. (2011): "La societat rural de les riberes del Xúquer davant la inundació de 1864", UHE Working Paper 2011_11, http: www.h-economica.uab.es/wps/20011_11.pdf

CASALS, V. (1996): Los ingenieros de montes en la España contemporánea (1848-1936), Barcelona, Ediciones del Serbal, 432 p.

CAVANILLES, A. J., (1795-98): Observaciones sobre la Historia Natural, Geografía, Agricultura, Población y Frutos del Reyno de Valencia, Madrid, Imprenta Real, 2 vols., 236 y 338 p.

DEL MORAL, L. (1995): "El origen de la organización administrativa del agua y de los estudios hidrológicos en España. El caso de la cuenca del Guadalquivir", Estudios Geográficos, LVI, 219, 371-393.

DUPRÉ, M. (1983): "Los montes: su estado y política en la cuenca del Júcar. Papel hidrológico-forestal", Cuadernos de Geografía, 32-33, 265-290.

DUPUIT, J. (1858): Des inondations. Examen des moyens proposés pour en prevenir le retour, $\mathrm{Pa}-$ ris, Victor Dalmont Editeur, 104 p.

FERRI, M. (2011): L'obra pública en el territori valencià durant la formació de l'estat liberal (1834-1868). La tasca dels enginyers de camins, Universitat de València, Tesi doctoral inèdita, València, $454 \mathrm{p}$.

GÓMEZ MENDOZA, J. (1992): Ciencia y política de los montes españoles (1848-1936), Madrid, ICONA, 206 p.

GÓMEZ MENDOZA, J. i ORTEGA CANTERO, N. (1989): "Inundaciones históricas y la génesis de la acción hidrológico-forestal en España (1855-1933)", dins: Gil Olcina, A., Morales Gil, A. (Ed.): Avenidas fluviales e inundaciones históricas en la cuenca del Mediterráneo, Alacant, Instituto Universitario de Geografía.

GÓMEZ ORTEGA, J., et al. (1879): "Memoria relativa a la inundación ocurrida en el año 1864 en el río Júcar", Anales de Obras Públicas, VI, nº 11, 6-142.

MARTÍ SORO, J. (1960): Historia de Villanueva de Castellón, Valencia, Imp. Nácher, 451 p.

MATEU, J. F. (1979): "Estudis de climatologia al País Valencià en el segle XIX”, Acta Geológica Hispánica, Homenatge a Lluís Solé, 14, 43-48.

MATEU, J. F. (1983 a): "La ciència i la tècnica davant les revingudes del Xúquer (1635-1905): notes preliminars", Cuadernos de Geografía, 32-33, 243-264.

MATEU, J. F. (1983 b): "La inundación de la Ribera del Júcar (20-21 de octubre de 1982)”, Estudios Geográficos, 170-171, 187-221.

MATEU, J. F. (1995): "Planificación hidráulica de las divisiones hidrológicas (1865-1899)", dins: Gil Olcina, A., Morales Gil, A. (Ed.): Planificación hidráulica en España, CAMP-Fundación Caja del Mediterráneo, Alicante, 69-105.

MATEU, J. F. (1996 a): "Las brigadas hidrológicas de la Junta General de Estadística (1859-1867)", Saitabi, Volum extraordinari, 251-281.

MATEU, J. F. (1996 b): "Precedentes históricos de la Confederación", Conmemoración del 60 aniversario de la Confederación Hidrográfica del Júcar, Confederación Hidrográfica del Júcar, Valencia.

MATEU, J. F. (2003): "El servicio de prevención y anuncio de crecidas en España (1863-1917)", Áreas, 23, 101-123.

MORÓS, J. (1847): Descripción geográfico-estadística del río Júcar, resultado de los reconocimientos practicados en dicho río en junio de 1845 y en abril de 1846, Valencia, Imp. Benito Monfort, $63 \mathrm{p}$. 
MURO, J. I., et al. (1996): Geografía, estadística y catastro en España (1856-1870), Barcelona, Ediciones del Serbal, $275 \mathrm{p}$.

PRO, J. (1992): Estado, geometría y propiedad. Los orígenes del catastro en España (1715-1941), Madrid, Ministerio de Economía y Hacienda, 419 p.

RIAÑO, M. (1886): “Necrológica. José Gómez Ortega”, Revista de Obras Públicas, 23, 365-367.

ROSSELLÓ, V. M. (2008): Cartografia històrica dels Països Catalans, València, Publicacions de la Universitat de València, 402 p.

S.V.A. (1864 a): "Inundación de varias comarcas agrícolas de la provincia de Valencia por el desbordamiento del río Júcar y otros torrentes", La Agricultura Valenciana, II, 20, 387-389.

S.V.A. (1864 b): "Remedios contra la inundación", La Agricultura Valenciana, II, 21, 406-408.

SÁENZ RIDRUEJO, F. (1990): Ingenieros de caminos del siglo XIX, Madrid, Colegio de Ingenieros de Caminos, Canales y Puertos, $413 \mathrm{p}$.

TARAZONA, I. (1912): “Treinta años (1864-1893) de observaciones efectuadas y deducidas en la estación meteorológica de la Universidad de Valencia", Asociación española para el progreso de las ciencias, Congrés de Granada.

TÉMEZ, J. R. (2006): "Las catástrofes hidrológicas españolas y el cambio climático", Revista de Obras Públicas, 3467, 7-11.

TORRES FAUS, F. (1987): "Salvador Bodí i Congròs (1814-1884) i el clima de la Ribera en el segle XIX. Una aproximació al seu pensament i al seu treball de meteorologia", Al-gezira. Revista d'Estudis Històrics - Ribera Alta, 3, 265-290.

VALLÉS, F. (1857): Études sur les inondations, leur causes et leurs effets, les moyens à mettre en oeuvre pour combattre leurs inconvénients et profiter de leurs avantages, Paris, Victor Dalmont Editeur, 528 p. 
